\title{
Effects of kerosene or distilled water as dielectric on electrical discharge alloying of superalloy Haynes 230 with Al-Mo composite electrode
}

\author{
Ching-Yuan Bai ${ }^{\mathrm{a}, \mathrm{b}}$, Chun-Hao Koo ${ }^{\mathrm{a}, *}$ \\ ${ }^{a}$ Department of Materials Science and Engineering, National Taiwan University, Taipei 106, Taiwan, ROC \\ ${ }^{\mathrm{b}}$ Department of Mechanical Engineering, National Defense University, Chung Cheng Institute of Technology, Ta-Hsi, Tao-Yuan 335, Taiwan, ROC
}

Received 8 October 2004; accepted in revised form 12 March 2005

Available online 23 May 2005

\begin{abstract}
The effects of kerosene and distilled water as dielectrics on the electrical discharge surface alloying of superalloy Haynes 230 are investigated. The 85 at.\% $\mathrm{Al}$ and 15 at.\% Mo composite electrode provided the surface alloying materials. The alloying results obtained using both positive and negative electrode polarities were compared. With negative electrode polarity and alloying in kerosene, many discontinuous piled-layers comprised mostly of $\mathrm{Al}_{3} \mathrm{Mo}_{8}$ and $\mathrm{AlMo}_{3}$ phases accumulate on the surface of the N-AlMo-Kero specimen, but alloying in distilled water was unsuccessful because of the difficulty of discharging under such an EDA condition. With positive electrode polarity, the alloyed layers constituted mainly of NiAl phase are formed on the EDA specimens, in either kerosene or distilled water. The alloyed layer of P-AlMo-Kero contains a mixture of NiAl, $\mathrm{Al}_{8} \mathrm{Mo}_{3}, \mathrm{Cr}_{23} \mathrm{C}_{6}$, and $\mathrm{Al}_{4} \mathrm{C}_{3}$, while the alloyed layer of P-AlMo-Water contains NiAl, $\mathrm{AlCr}$, $\mathrm{Al}_{5} \mathrm{Cr}$, and $\mathrm{Al}_{2} \mathrm{O}_{3}$ phases. The P-AlMo-Water exhibits the highest hardness, whereas the P-AlMo-Kero has the smallest surface roughness of all the EDA specimens. The superalloy Haynes 230 and the EDA specimens are subjected to isothermal oxidation at $1000{ }^{\circ} \mathrm{C}$ in static air. Analyses of oxidation kinetics indicate that the P-AlMo-Water and the P-AlMo-Kero specimens are more resistant to oxidation than the unalloyed superalloy; and the P-AlMo-Kero specimen has the best oxidation resistance among all tested specimens.
\end{abstract}

(C) 2005 Elsevier B.V. All rights reserved.

Keywords: Knoop hardness test; Roughness; Aluminium; Molybdenum; Nickel alloy; Electrical discharge alloying (EDA)

\section{Introduction}

The development of industrial technology depends on the use of materials as structural components in increasingly extreme and aggressive conditions, such as in high temperature erosion and corrosion, electrochemical corrosion, and/ or abrasive wear situations. Most forms of degradation or destruction resulted from severe environmental conditions are initiated at the surface of materials. Accordingly, many efforts have recently been made to develop surface modification, including the developments of coating $[1,2]$ and surface alloying $[3,4]$ techniques and the production of

\footnotetext{
* Corresponding author. Tel.: +886 223634097 ; fax: +886223634562. E-mail addresses: cybai@ccit.edu.tw (C.-Y. Bai), chkoo@ccms.ntu.edu.tw (C.-H. Koo).
}

new surface materials whose properties differ from those of the substrate; such materials may be impossible to obtain by traditional methods.

Electrical discharge alloying (EDA) is a new surface alloying technique that uses a green-compact composite electrode [5-8] as an alloying material to improve the surface chemical and mechanical properties of structural materials. During electrical discharge, the thermal energy converted from electrical energy generates a channel of plasma between the cathode and the anode [9] at temperatures between 8000 and $12,000{ }^{\circ} \mathrm{C}$ [10], melting the surface of the electrode and workpiece, such that the electrode materials are induced into the molten surface of workpiece. Furthermore, the working fluid is decomposed at these temperatures, enriching the surface of a workpiece by the addition of the dielectric elements. Different dielectrics exhibit dissimilar cooling rates and compositions, so the 
Table 1

The chemical composition of the experimental superalloy Haynes 230

Elements Ni Cr W Co $\quad \mathrm{Fe} \quad$ Mo Mn Si Al C $\quad$ La

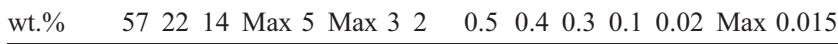

reaction time and products of EDA are unlike in different dielectrics. The choice of dielectric, therefore, is critical to the EDA process.

Among the most commonly used dielectrics, kerosene has been often employed in the EDA of various workpieces [11-13]. However, when kerosene is used as a dielectric, the carbon that is decomposed from kerosene accumulates on the machining surface and then diffuses or is mixed into the molten surface of the workpiece during the EDA process. Additionally, kerosene is flammable and the gaseous chemicals produced from kerosene are poisonous [14]. However, the distilled water is nonflammable and harmless. Moreover, the oxides are formed and dispersed on the surface layer of the workpiece, increasing its surface hardness and corrosion resistance, as the oxygen that is decomposed from distilled water reacts with the elements of the workpiece and the electrode during the EDA process. Therefore, distilled water may be a suitable dielectric for EDA. This study investigates the potential to use distilled water as a dielectric in EDA using an Al-Mo composite electrode. The effects of different dielectrics, such as kerosene and distilled water in EDA, on surface alloying and surface properties are also examined.

\section{Experimentation}

\subsection{Alloying materials}

The workpiece used in this experiment is the Ni-based superalloy Haynes 230, manufactured by Haynes International Inc., as shown in Table 1. The alloying materials include 85 at.\% $\mathrm{Al}$ powder of about $15 \mu \mathrm{m}$ and 15 at.\% Mo powder of about $10-15 \mu \mathrm{m}$. These powders were mixed in a cylindrical-shape blender for $10 \mathrm{~h}$, and were then fabricated into a green-compact tablet by powder metallurgy under 80 $\mathrm{MPa}$ at $250{ }^{\circ} \mathrm{C}$ for $50 \mathrm{~min}$. Finally, the tablet was bonded to an electrolytic copper rod, using a conductive coppermounting compound, to form a finished Al-Mo composite electrode.

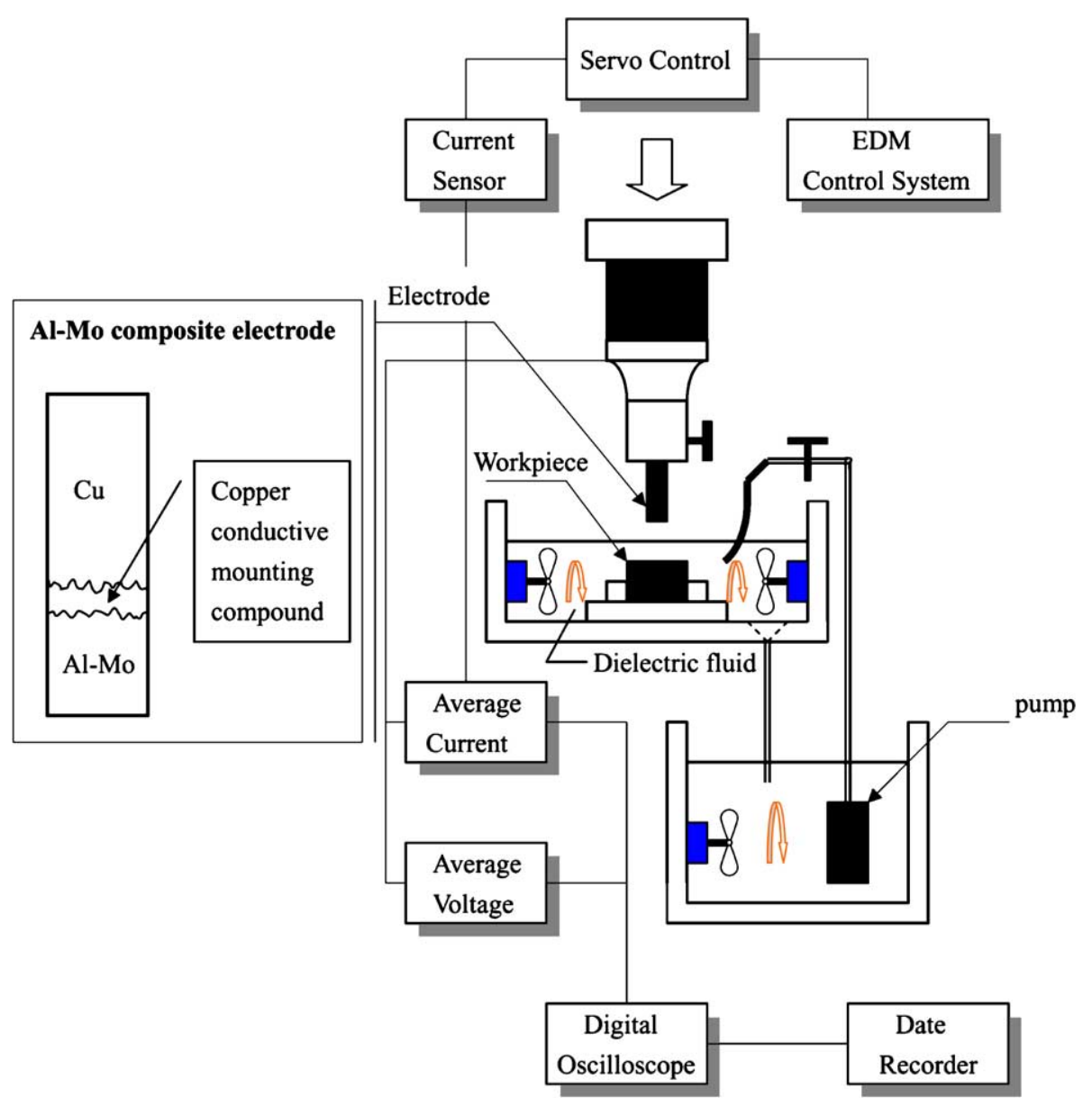

Fig. 1. Schematic diagram of experimental setup for this research. 
Table 2

The EDA experimental conditions

\begin{tabular}{ll}
\hline Working parameters & Description \\
\hline Workpiece & $\begin{array}{l}\text { Superalloy Haynes } 230 \\
(15 \mathrm{~mm} \times 15 \mathrm{~mm} \times 2 \mathrm{~mm})\end{array}$ \\
Electrode & Al-Mo composite electrode $(\varnothing 12 \mathrm{~mm})$, \\
& $(85$ at.\% Al-15 at.\% Mo) \\
& $(1)$ Kerosene \\
Dielectric & (2) Distilled water \\
& Positive (+)/negative (-) \\
Electrode polarity & $10 \mathrm{~A}$ \\
Discharge current, $I_{\mathrm{p}}$ & $600 \mu \mathrm{s}$ \\
Pulse duration, $\tau_{\mathrm{p}}$ & 0.33 \\
Duty factor & $100 \mathrm{rpm}$ \\
Rotation speed of electrode & $360 \mathrm{~s}$ \\
Working time &
\end{tabular}

$\mathrm{Al}-\mathrm{Mo}$ composite electrode, forming pressure/temperature/time: $80 \mathrm{MPa}$ $250{ }^{\circ} \mathrm{C} / 50 \mathrm{~min}$.

\subsection{EDA process}

The EDA process was performed on a die sinking electrical discharge machine, as shown in Fig. 1. Either commercial kerosene or distilled water was used as the dielectric during surface alloying. Both positive and negative electrode polarities were used to compare the results of alloying with electrodes of different polarities. Table 2 lists actual experimental conditions of the EDA process.

When the $\mathrm{Al}-\mathrm{Mo}$ electrode with negative polarity was used in distilled water, the alloying process was unsuccessful because of the difficulty of discharging under such an EDA condition. Therefore, three surface alloying specimens were prepared via the EDA processes. Table 3 gives the name of the specimens used in this study and the corresponding EDA conditions.

\subsection{Analysis and testing of alloyed specimens}

The alloyed specimens were cut to $\varnothing 12 \mathrm{~mm}$ by wire electrical discharge machining, and then ultrasonically cleaned with acetone and deionized water. The various phases of the alloyed specimens was characterized by X-ray diffraction using monochromatic $\mathrm{Cu}-\mathrm{K} \alpha$ radiation (wavelength $=1.542 \AA$ ). The surface morphology, the crosssectional microstructure, and the chemical composition of the alloyed specimens were examined by scanning electron microscopy (SEM), X-ray energy dispersive spectrometry (EDS), and electron probe microanalysis (EPMA). Precision profilometry was employed to measure the surface roughness. Five random measurements presented by $\mathrm{Ra}$ were

Table 3

The name of EDA specimens and corresponding conditions

\begin{tabular}{llll}
\hline Specimen name & Electrode & $\begin{array}{l}\text { Electrode } \\
\text { polarity }\end{array}$ & Dielectrics \\
\hline P-AlMo-Kero & Al-Mo composite & + & Kerosene \\
N-AlMo-Kero & Al-Mo composite & - & Kerosene \\
P-AlMo-Water & Al-Mo composite & + & Distilled water \\
\hline
\end{tabular}

averaged to obtain the typical surface roughness. The hardness profiles of the EDA specimens were measured along the depth of the cross-section of alloyed layers, using a Knoop hardness tester with a load of $25 \mathrm{~g}$ and a loading time of $15 \mathrm{~s}$. In the high temperature oxidation test, the EDA specimens, which are alloyed on double-side surfaces, and unalloyed superalloy underwent isothermal oxidation at $1000{ }^{\circ} \mathrm{C}$ in static air for a period of 41 days, but were weighted every $24 \mathrm{~h}$ to calculate the oxidation kinetics.

\section{Results}

\subsection{Phase constitution and microstructure of alloyed layers}

Fig. 2(a)-(d) show the XRD spectra of unalloyed Haynes 230 and three EDA specimens. The XRD results demonstrate that the alloyed layer of P-AlMo-Kero in Fig. 2(c) contains a mixture of $\mathrm{NiAl}, \mathrm{Al}_{8} \mathrm{Mo}_{3}, \mathrm{Cr}_{23} \mathrm{C}_{6}$, and $\mathrm{Al}_{4} \mathrm{C}_{3}$; while $\mathrm{NiAl}, \mathrm{AlCr}_{2}, \mathrm{Al}_{5} \mathrm{Cr}$, and $\mathrm{Al}_{2} \mathrm{O}_{3}$ phases are detected in the alloyed layer of P-AlMo-Water in Fig. 2(b). The NiAl peaks in the XRD spectra of P-AlMo-Kero and PAlMo-Water are much more intensive than the other phases, indicating that the $\mathrm{NiAl}$ phase is the main constituent in the

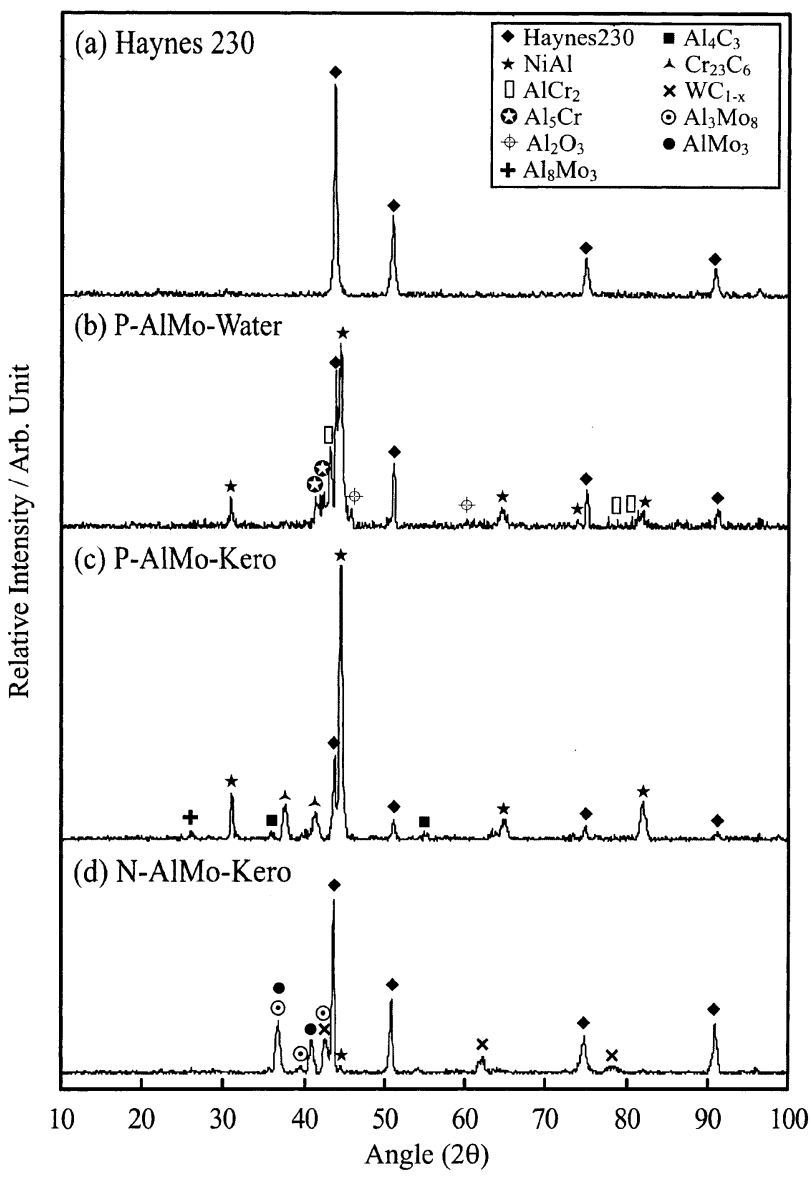

Fig. 2. XRD spectra of (a) unalloyed superalloy Haynes 230, and three EDA specimens: (b) P-AlMo-Water, (c) P-AlMo-Kero, and (d) N-AlMo-Kero. 

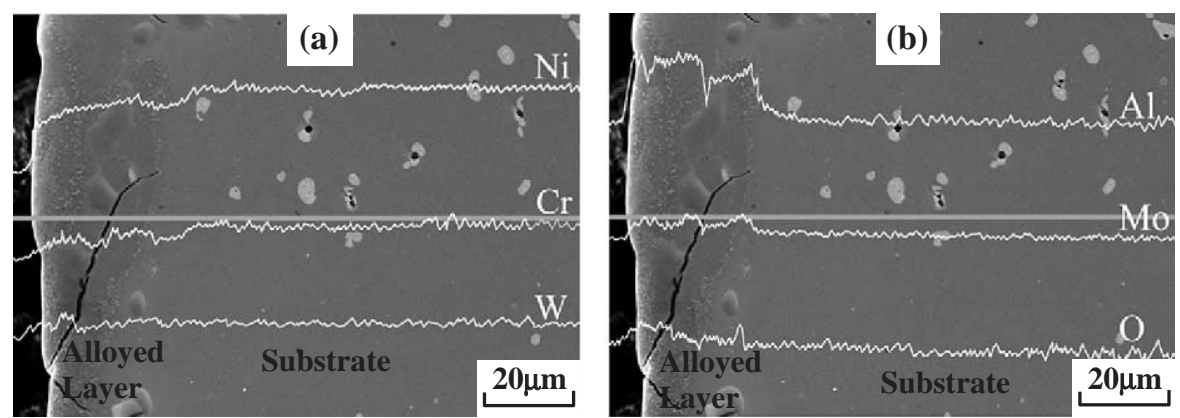

Fig. 3. Cross-sectional SEM (SEI) micrographs with EDS line scan for (a) Ni, Cr, W, and (b) Al, Mo, O of the P-AlMo-Water specimen.

alloyed layers of the P-AlMo-Kero and P-AlMo-Water specimens. However, the XRD spectra of N-AlMo-Kero include $\mathrm{Al}_{3} \mathrm{Mo}_{8}, \mathrm{AlMo}_{3}$, and $\mathrm{WC}_{1-x}$, but the $\mathrm{NiAl}$ peaks are very weak.

Fig. 3 shows SEM cross-sectional micrographs with EDS line scan of the P-AlMo-Water specimen. The alloyed layer of P-AlMo-Water, with many white precipitates, has a thickness of approximately $30 \mu \mathrm{m}$. The major elements of the substrate, such as $\mathrm{Ni}$ and $\mathrm{Cr}$, and the electrode elements, $\mathrm{Al}$ and $\mathrm{Mo}$, are distributed uniformly in the alloyed layer. A gradual decrease in the $\mathrm{Ni}$ and $\mathrm{Cr}$ concentrations from substrate to surface of the alloyed layer is observed, while the signal intensities of $\mathrm{Al}$ and Mo increase with the distance from substrate to the surface. The compositional gradient in the elemental distribution is associated with a strong bonding between the alloyed layer and the substrate of P-AlMo-Water specimen. However, cross-sectional micrographs reveal that the thickness of the alloyed layer is inhomogeneous and many serious cracks go through this layer. These defects in the alloyed layer degrade the surface properties of the P-AlMo-Water specimen.

Fig. 4(a)-(e) present cross-sectional SEM micrographs of P-AlMo-Kero specimen and the corresponding X-ray maps of $\mathrm{Ni}, \mathrm{Cr}, \mathrm{Al}$, and Mo. The thickness of the alloyed layer that adheres strongly to the substrate is about 40-50 $\mu \mathrm{m}$. The X-ray maps demonstrate that the electrode elements $\mathrm{Al}$ and Mo are uniformly distributed in the alloyed layer with a compositional gradient that decreases gradually from surface to substrate. Moreover, the signal of Al is stronger than that of Mo, indicating that a fair amount of $\mathrm{Al}$ and a little Mo are dissolved in the alloyed layer.

Fig. 5 presents typical SEM cross-sectional images of $\mathrm{N}$ AlMo-Kero. Unlike the formation of a smooth and homogeneous alloyed layer on the surface of P-AlMo-Kero,

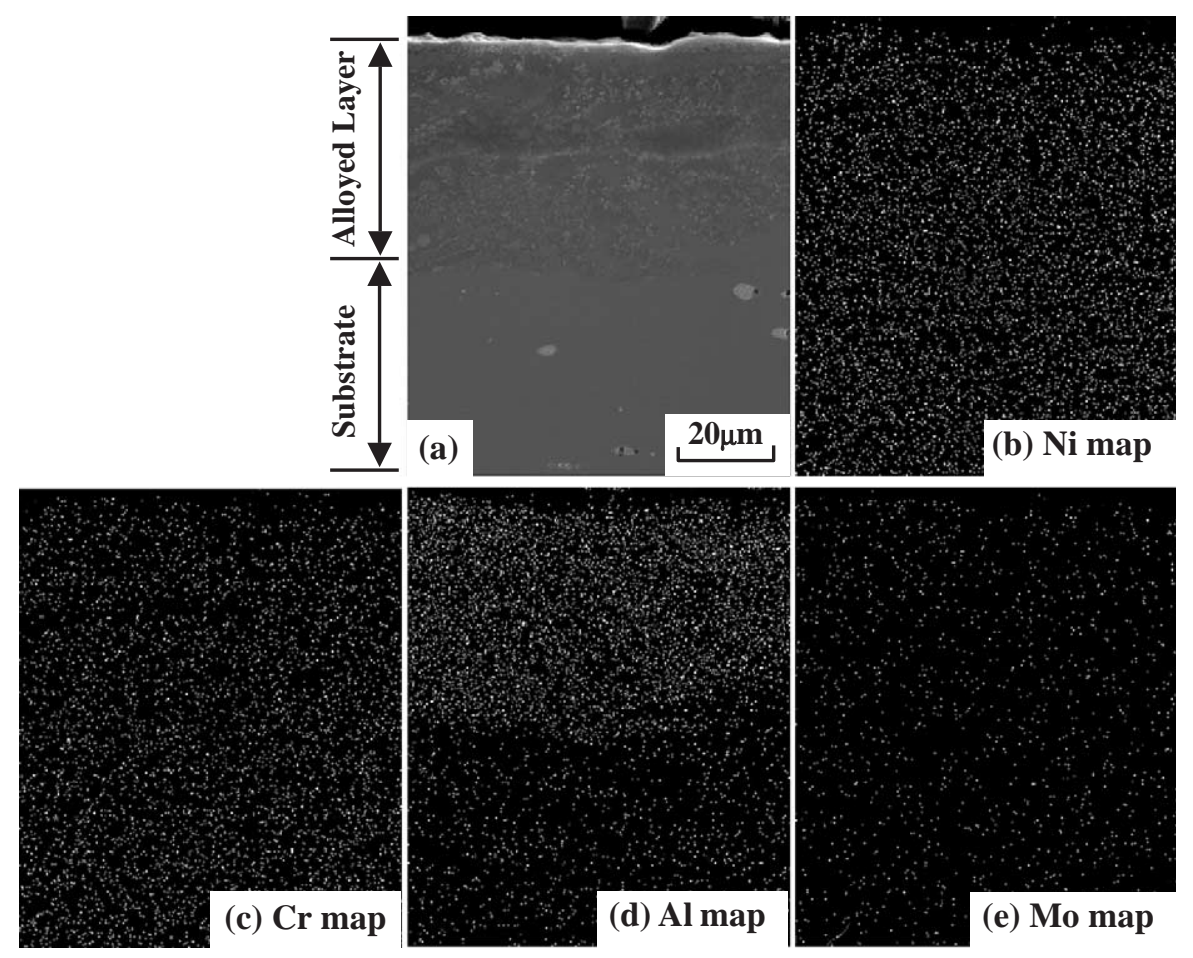

Fig. 4. (a) Cross-sectional SEM (SEI) micrograph of the P-AlMo-Kero specimen, and followed by X-ray maps of (b) Ni, (c) Cr, (d) Al, and (e) Mo in (a). 


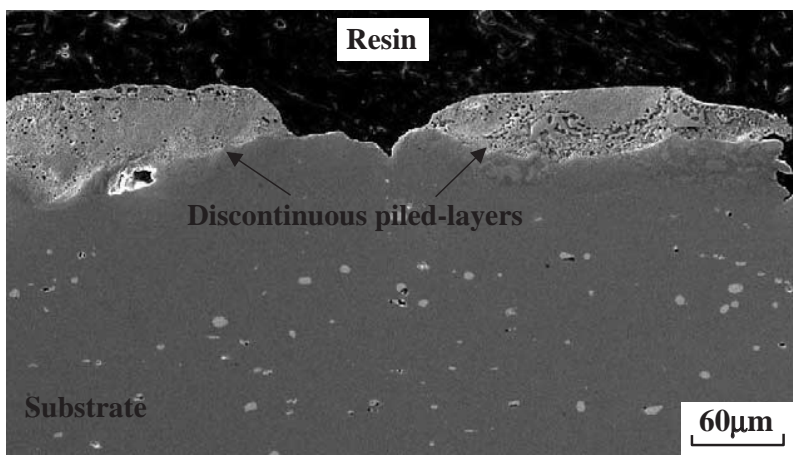

Fig. 5. Cross-sectional SEM (SEI) micrographs of the N-AlMo-Kero specimen.

discontinuous piled-layers are formed, and attached to the surface of N-AlMo-Kero; the surface of this specimen becomes severely cracked. Fig. 6(a) $-(\mathrm{g})$ show backscattered electron-image (BEI) micrographs of the N-AlMoKero specimen with piled-layers and corresponding X-ray maps of $\mathrm{Ni}, \mathrm{Cr}, \mathrm{W}, \mathrm{Al}, \mathrm{Mo}$, and $\mathrm{C}$. They indicate that the piled-layer includes several voids and that the elemental distribution of piled-layer is inhomogeneous. The piledlayer contains a little $\mathrm{Al}$, but the substrate near the piledlayer/substrate interface contains more. Furthermore, the piled-layers are enriched with Mo, indicating that the $\mathrm{Al}$ and Mo tend to separate from the mixture of electrode droplets when the mixture accumulates on surface of the superalloy under such EDA condition.

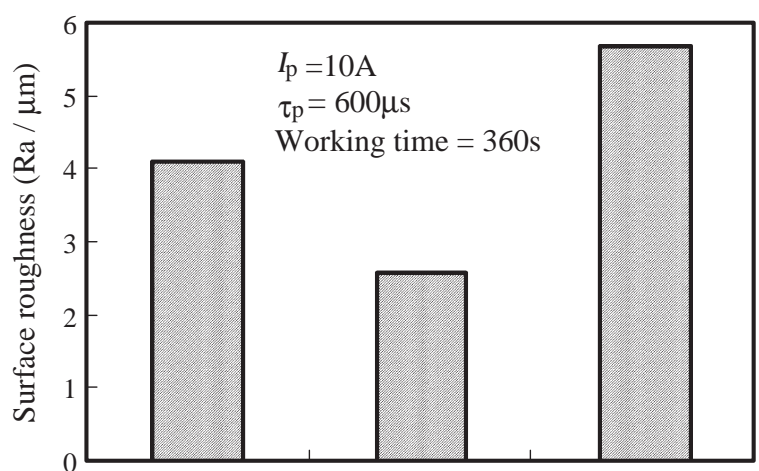

(a)

(b)

(c)

EDA specimens

Fig. 7. Surface roughness of (a) P-AlMo-Water, (b) P-AlMo-Kero, and (c) N-AlMo-Kero specimens.

\subsection{Surface conditions}

Fig. 7 shows the surface roughness of three EDA specimens. Fig. 8(a)-(c) present the surface morphologies of these alloying specimens.

The P-AlMo-Water specimen with $\mathrm{Ra}=4.11 \mu \mathrm{m}$ shows rough morphology and its surface has many serious cracks. Moreover, the surface contains various white precipitates distributed over a wide range of sizes. The cross-sectional view of the alloyed layer presented in Fig. 3 also shows precipitates and cracks. EDS analysis indicates that the white precipitates that contain

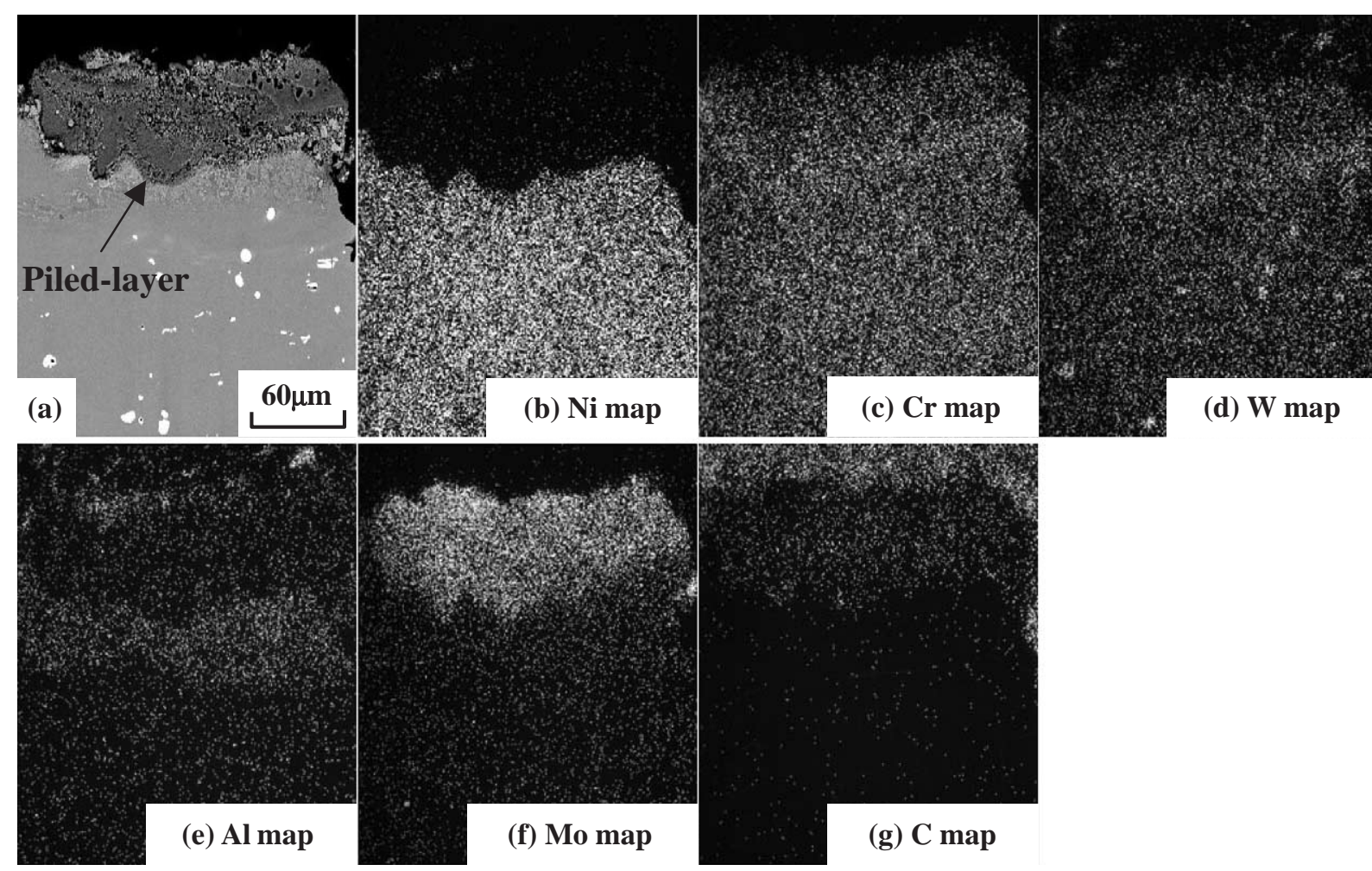

Fig. 6. (a) Cross-sectional SEM (BEI) micrograph of the N-AlMo-Kero specimen, and followed by X-ray maps of (b) Ni, (c) Cr, (d) W, (e) Al, (f) Mo, and (g) $\mathrm{C}$ in (a). 

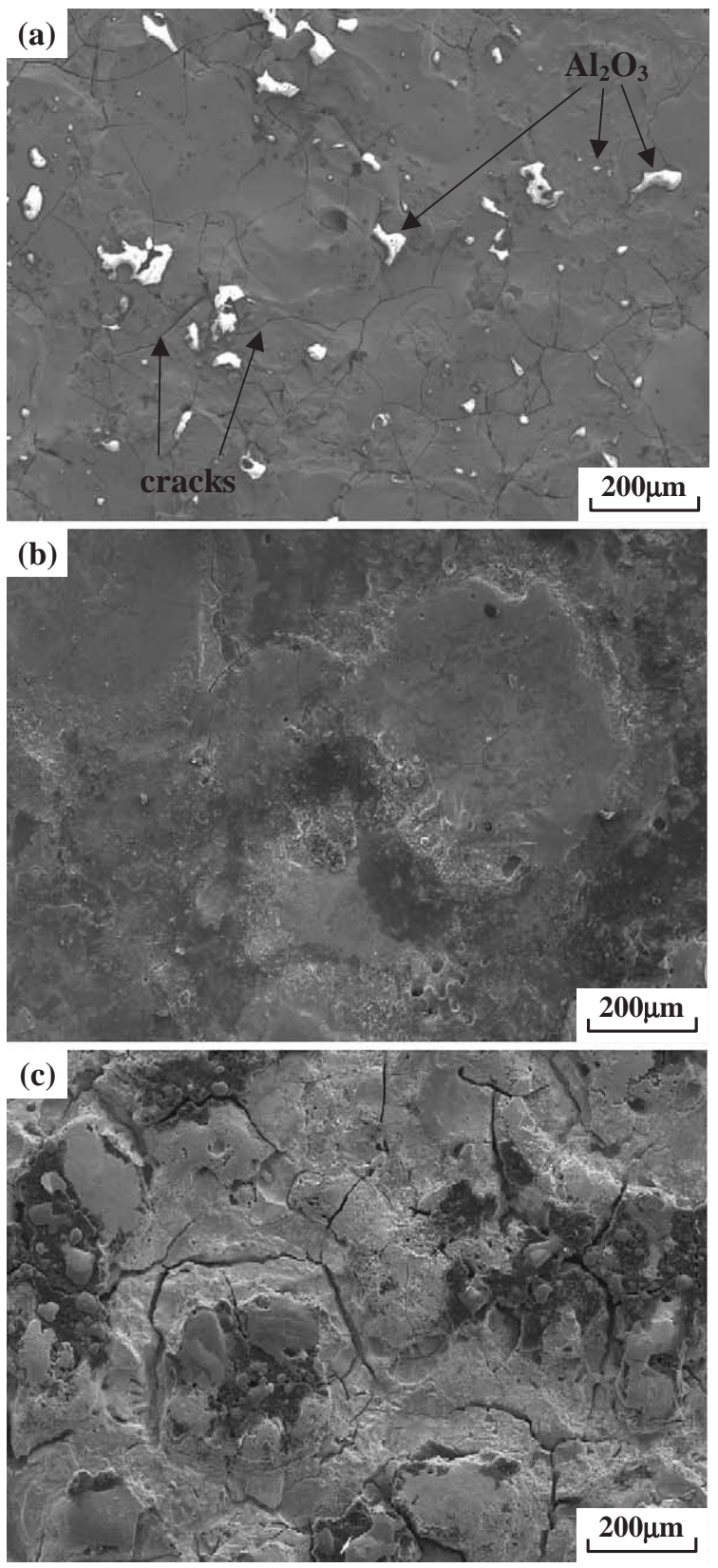

Fig. 8. Surface morphologies of (a) P-AlMo-Water, (b) P-AlMo-Kero, and (c) N-AlMo-Kero specimens.

$\mathrm{Al}$ and $\mathrm{O}$ are $\mathrm{Al}_{2} \mathrm{O}_{3}$ phase, as determined from the XRD results.

With respect to discharging in kerosene, the P-AlMoKero specimen reveals the least roughness $(\mathrm{Ra}=2.62 \mu \mathrm{m})$ and the finest surface morphology. However, the NAlMo-Kero with a roughness of $\mathrm{Ra}=5.68 \mu \mathrm{m}$ demonstrates the coarsest topography; its surface covers many rough mounds. EDS analyses indicate that the rough mounds contain fair amounts of $\mathrm{Mo}$ and a little $\mathrm{W}, \mathrm{Cr}$, $\mathrm{Al}$, and $\mathrm{C}$. The rough mounds show a style of discontinuous piled-layers in cross-sectional observation of this specimen.

\subsection{Hardness measurements}

The hardness of N-AlMo-Kero was measured on a crosssection without piled-layers, to prevent inconsistent results concerning discontinuous piled-layers, whereas the hardness of the P-AlMo-Water and P-AlMo-Kero specimens was measured in arbitrary cross-section. Fig. 9 shows the crosssectional hardness profiles of P-AlMo-Water, P-AlMo-Kero, and N-AlMo-Kero specimens. The maximum hardness of all EDA specimens is at the location closed to the surface, and the measured hardness values of P-AlMo-Water, PAlMo-Kero, and N-AlMo-Kero specimens are 1138, 1086, and $720 \mathrm{HK}$, respectively. The P-AlMo-Water specimen exhibits the highest surface hardness. In P-AlMo-Kero specimen the hardness is higher than that of the substrate, at a depth of about $50-60 \mu \mathrm{m}$, which is greater than the corresponding depth in the other two EDA specimens. Moreover, the hardness profiles of P-AlMo-Water and PAlMo-Kero agree with the analysis of the compositional gradient in the alloyed layers, shown in Figs. 3 and 4.

\subsection{Kinetics of isothermal oxidation}

High temperature oxidation tests were performed to evaluate the oxidation resistance of unalloyed superalloy and various EDA specimens. Fig. 10 plots the weight change per unit area vs. oxidation time for the test performed at $1000{ }^{\circ} \mathrm{C}$ in air. During exposure, the kinetic curve of the superalloy Haynes 230 follows the parabolic rate law for $600 \mathrm{~h}$ but shows a gradual weight loss after 600 $\mathrm{h}$, revealing that oxide scales formed on the surface of the superalloy as a diffusion barrier in the early and intermediate stages of oxidation. However, the superalloy does not exhibit long-term oxidation resistance.

With regard to EDA specimens, the kinetic curve of NAlMo-Kero shows serious weight loss in the initial stage of oxidation, indicating that the oxidation resistance of the $\mathrm{N}$ AlMo-Kero specimen is even worse than that of the

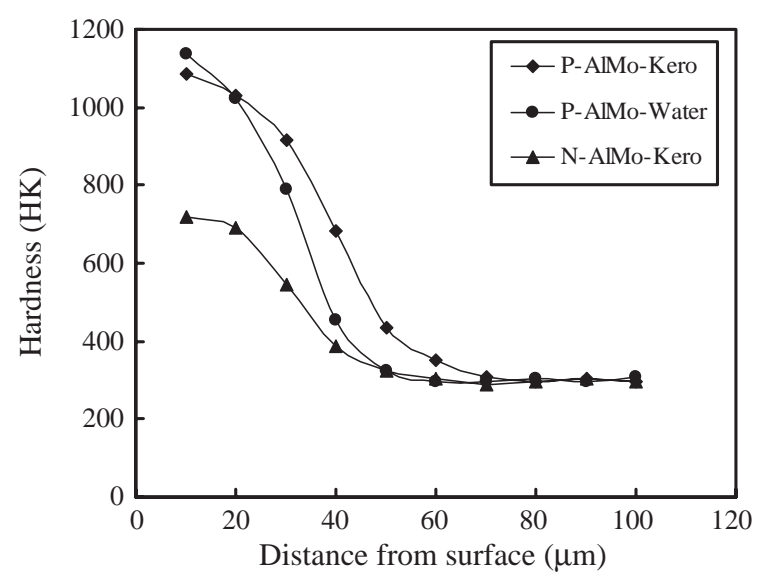

Fig. 9. Hardness profiles along the depth of cross-section of three EDA specimens. (load: $25 \mathrm{~g}$, loading time: $15 \mathrm{~s}$ ) 


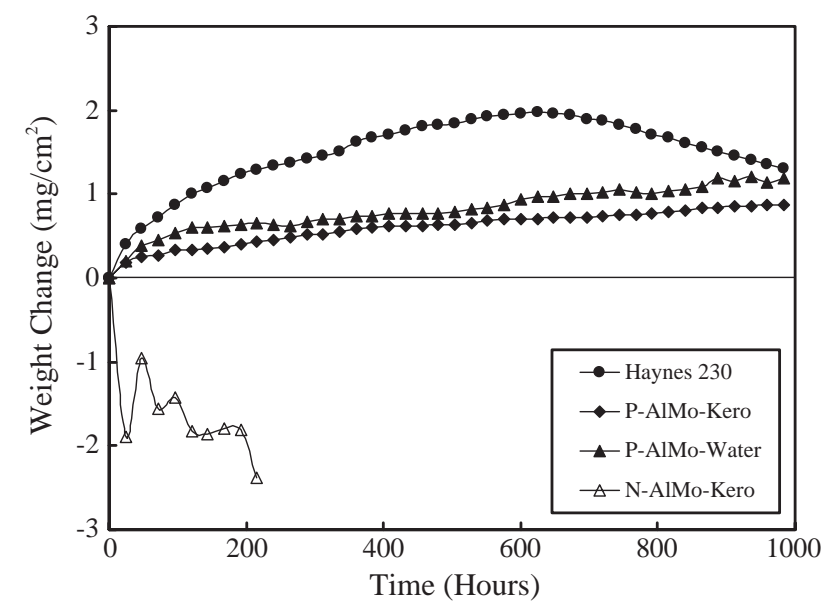

Fig. 10. The isothermal oxidation kinetics of unalloyed superalloy Haynes 230 and three EDA specimens at $1000{ }^{\circ} \mathrm{C}$ in static air.

unalloyed superalloy. The specimen deteriorated quickly and failed catastrophically because of the formation of volatile molybdenum oxide [15]. However, the isothermal oxidation behavior of P-AlMo-Water and P-AlMo-Kero specimens demonstrate a very low weight gain, even after 41 days of exposure, revealing that the alloyed layer formed on the surface of these specimens produces protective oxide layers during exposure in air, establishing long-term oxidation resistance. Furthermore, the oxidation of PAlMo-Kero is slower than that of P-AlMo-Water, indicating that the oxidation resistance of P-AlMo-Kero exceeds that of the P-AlMo-Water specimen.

\section{Discussion}

This work attempts to investigate the possibility of using distilled water as a dielectric fluid in the EDA process. The alloying results and surface properties of EDA specimens were examined to evaluate the advantages and disadvantages of various EDA conditions and the stability of the EDA process. Based on the experimental results, the influence of the electrode polarity, the forming conditions of the electrode, and the effects of different dielectrics are discussed.

\subsection{Influence of electrode polarity}

During the EDA process, the alloyed layer is successfully produced on the superalloy surface using an Al-Mo electrode with positive polarity in pure kerosene or in distilled water dielectrics. Surface alloying is ineffective when the electrode polarity is negative. The alloying results change with the electrode polarity. The discharge spot of the anode is larger than that of the cathode, and the current or energy density of the anode is less than that of cathode under the same EDM conditions [16-18]. When the electrode polarity is negative, the current density on the electrode is larger than that on the electrode with positive polarity. A high electrode energy density results in high electrode consumption, and consequently large amounts of electrode droplets are produced. On the other hand, the energy density on the surface of the anode workpiece is lower than that on the cathode workpiece. A low discharge current density yields a shallow molten surface on the workpiece, and the shallow molten zone may quickly resolidify in the dielectric fluid. Therefore, large amounts of electrode materials cannot effectively mix into the workpiece surface. Most electrode materials are attached to the substrate surface to form discontinuous piled-layers when kerosene dielectric was used, but the alloying process was unsuccessful because of the difficulty of discharging when the distilled water was used as dielectric.

When the composite electrode is the anode, the larger discharge spot on the anode electrode resulted in a wider melting zone than that on the cathode electrode. Although the current density on the anode is lower than that on the cathode, the discharge energy on the anode is sufficient to disintegrate appropriate quantities of alloying materials (Al and Mo) from the weakly bonding electrode. Then, the carbon or oxygen decomposed from dielectric fluids reacts with the alloying materials and is transferred to the molten surface of the superalloy. Furthermore, the surface of the cathode workpiece yields a deep molten zone, because of the large current density, so the alloying materials transferred from the electrode successfully dissolve into the molten substrate surface and react with the elements of the substrate to produce an alloyed layer.

In recent years, many EDAs [6,8,19] of aluminum alloys have used a green-compact electrode with negative polarity in kerosene dielectric to generate alloyed or modified layers. The modified layers always contain hard particles such as carbides and secondary binder phases, to enhance the wear and corrosion resistance of the alloyed surface. In this work, the EDA result of superalloy Haynes 230 with negative AlMo composite electrode shows that only a few carbides are formed and a little $\mathrm{Al}$ is dissolved in the alloyed layer of the superalloy. Moreover, various discontinuous piled-layers attached to the surface of the superalloy, which is detrimental to the surface properties. Therefore, the results of the surface alloying of the superalloy obtained using a negative electrode are worse than those obtained using a positive electrode polarity, when the EDA process uses a weakly bonding electrode.

\subsection{Electrode forming conditions}

Measurements of surface roughness show that the PAlMo-Kero specimen has a lower surface roughness and a finer surface morphology than that of the N-AlMo-Kero specimen. The fine surface morphology of the P-AlMokero specimen is attributable to the fact that the Al-Mo composite electrode has a low thermal conductivity, allowing the alloying materials to disintegrate from the 
electrode and reside on the workpiece surface, then mixing with molten surface of superalloy, smoothing the surface and reducing the number of cracks. However, the surface roughness of N-AlMo-Kero specimen is very high because high electrode consumption results in a large amount of electrode materials, attaching to the surface of the N-AlMo-Kero specimen. For the same reason, the surface alloying of superalloy Haynes 230 with the negative electrode polarity is less effective than that with the positive electrode polarity. This inference is based on the use of a weakly bonding electrode that contains materials with high melting point. It indicates that the EDA outcome is related to not only EDA parameters but also electrode conditions, such as the composition, the powder size, and the forming temperature and pressure of the electrode.

Tsai [13] et al. studied the EDM performance of $\mathrm{Cr} / \mathrm{Cu}$ based composite electrodes; the surface roughness of the workpiece (AISI 1045) obtained using a positive electrode exceeded that obtained using a negative electrode, because the anode has a larger discharge spot than the cathode, resulting in a wider melting zone on the weakly bonding electrode and producing more particles that dropped and accumulated on the surface of the workpiece. Their composite electrode was fabricated from a mixture of $\mathrm{Cr}$ powders $(45 \mu \mathrm{m})$ and $\mathrm{Cu}$ powders $(53 \mu \mathrm{m})$ that contain resin, at $200{ }^{\circ} \mathrm{C}$ and $20 \mathrm{MPa}$. The bonding of the mixture powders in such a composite electrode was very weak and leading to a high electrode wear when the anode was the composite electrode. Additionally, the size of the mixture powders was too large to be mixed completely into the molten surface of the workpiece under those experimental conditions. However, a smooth alloyed layer formed on the surface of the superalloy when the electrode polarity was positive, because the $\mathrm{Al}-\mathrm{Mo}$ mixture in the electrode dissolved completely into molten zone of the substrate. Accordingly, the powder of size $10-15 \mu \mathrm{m}$ is suitable for fabricating an $\mathrm{Al}-\mathrm{Mo}$ composite electrode to alloy the surface of the superalloy by EDA, under the experimental conditions applied in this research.

In summary, high electrode consumption causes the alloying materials ineffectively to dissolve into the workpiece, regardless of whether the electrode polarity is positive or negative, so the surface alloying effect is suppressed and the surface properties of a workpiece are degraded. Therefore, EDA parameters that are appropriate for a specific electrode must be further investigated.

\subsection{Effects of dielectrics}

The XRD spectra of EDA specimens, shown in Fig. 2, demonstrate that many complex and metastable phases, besides equilibrium phases, are detected in the alloyed layers, because of the quenching effect of rapid melting and resolidification. During electrical discharge in dielectric fluids, the molten mixture of the electrode and the substrate resolidifies very rapidly, and changes the microstructure and/or phase constitution of the machined or alloyed surface layer. The electrical discharge machined (EDM) layer is called the heat-affected zone (HAZ). The layers of a machined workpiece are generally categorized into three main types, according to their hardness-recast layers, intermediate layers and unaffected matrix layers, in order of decreasing hardness [20,21]. The microstructure and characteristics of HAZ (in the EDM process) or the alloyed layer (in the EDA process) are related to the physical properties of the dielectric fluids, such as thermal conductivity and electrical conductivity.

The thermal conductivity of distilled water is about four times that of the kerosene [22], and the rate of resolidification of molten substrate in distilled water exceeds that in kerosene. Consequently, the maximum hardness and the surface roughness of P-AlMo-Water exceed those of PAlMo-Kero. Moreover, the high resolidification rate of molten substrate in distilled water results in the shallowness and uneven thickness of the alloyed layer of P-AlMo-Water, and numerous serious cracks are present throughout the alloyed layer of which specimen. Rough surface morphology and cracks in the alloyed layer increase the total exposure areas of P-AlMo-Water when the EDA specimens are subjected to oxidation at high temperature, so the weight gain of P-AlMo-Water is higher than that of the P-AlMoKero specimen throughout the period of oxidation. Furthermore, if necessary, the P-AlMo-Water specimen with cracks in the alloyed layer undergoes high temperature cyclic oxidation; the protective oxide scales would be easily damaged because of the concentration of thermal stress in the zone near the cracks.

When the Al-Mo electrode with negative polarity is used in distilled water, large amounts of droplets are produced from the electrode; the electrode droplets then react with the oxygen that is decomposed from distilled water, to form a large number of metal oxides, which is ceramics, during electrical discharge. The electrical conductivity of the dielectric fluid becomes disproportionately low because considerable quantities of metal oxides lie between the electrode and the workpiece. Accordingly, the metal oxides interfere with the discharge proceeding, and the discharge state becomes unstable. Therefore, the alloying process was unsuccessful because of the difficulty of discharging under these EDA conditions.

\section{Conclusions}

1. An Al-Mo composite electrode with positive polarity was used in distilled water or kerosene dielectric to form an alloyed layer, with compositional gradient, on the surface of the superalloy Haynes 230. The alloyed layer of P-AlMo-Water contains a mixture of $\mathrm{NiAl}, \mathrm{AlCr}_{2}$, $\mathrm{Al}_{5} \mathrm{Cr}$, and $\mathrm{Al}_{2} \mathrm{O}_{3}$ phases. The $\mathrm{NiAl}, \mathrm{Al}_{8} \mathrm{Mo}_{3}, \mathrm{Cr}_{23} \mathrm{C}_{6}$, 
and $\mathrm{Al}_{4} \mathrm{C}_{3}$ are present in the alloyed layer of P-AlMoKero specimen.

2. When a negative Al-Mo electrode is used in kerosene, many discontinuous piled-layers with $\mathrm{Al}_{3} \mathrm{Mo}_{8}$ and $\mathrm{AlMo}_{3}$ phases accumulate on the surface of N-AlMoKero, because the electrode consumption is high and the molten zone on this specimen is shallow. The alloying process in distilled water was unsuccessful because numerous metal oxides interfere with the discharge proceeding when a negative electrode polarity is selected.

3. The maximum hardness of P-AlMo-Water exceeds that of P-AlMo-Kero because the resolidification rate of molten substrate in distilled water exceeds that in kerosene. However, the P-AlMo-Kero specimen has the finest surface morphology, the thickest alloyed layer, and the slowest oxidation rate of all EDA specimens.

4. The alloyed layer formed on the P-AlMo-Kero or the PAlMo-Water specimen increases the high temperature oxidation resistance of the superalloy Haynes 230. The high temperature oxidation resistance of all the tested specimens, from best to worst, follows the order, PAlMo-Kero, P-AlMo-Water, superalloy Haynes 230, and N-AlMo-Kero.

5. The compositional and structural analyses, the surface roughness measurements, and the high temperature oxidation test of the EDA specimens all indicate that the surface alloying effect in kerosene is better than that in distilled water.

6. The Al-Mo composite electrode provides the surface alloying materials during EDA process. The EDA outcome is related to electrode conditions; the EDA parameters that are appropriate for a specific electrode must be further studied.

\section{References}

[1] B.G. Rhee, H.Y. Sohn, High Temp. Mater. Process. 21 (2002) 217.

[2] L. Swadzba, B. Formanek, A. Maciejny, Int. J. Mater. Prod. Technol. 8 (1993) 155.

[3] J. de Damborenea, Surf. Coat. Technol. 101 (1998) 377.

[4] P. Marcus, Electrochim. Acta 43 (1998) 109.

[5] A. Gangadhar, M.S. Shunmugam, P.K. Philip, Wear 143 (1991) 45.

[6] Y. Tsunekawa, M. Okumiya, N. Mohri, E. Kuribe, Mater. Trans., JIM 38 (1997) 630.

[7] M.P. Samuel, P.K. Philip, Int. J. Mach. Tools Manuf. 37 (1997) 1625.

[8] M. Okumiya, Y. Tsunekawa, K. Fukaya, N. Mohri, Mater. Trans. 42 (2001) 1717.

[9] E.I. Shobert, in: E.C. Jameson (Ed.), Electrical Discharge Machining: Tooling, Methods and Applications, Society of Manufacturing Engineers, Dearborn, MI, 1983, p. 3.

[10] G. Boothroyd, A.K. Winston, Fundamentals of Machining and Machine Tools, Marcel Dekker, Inc., New York, 1989, p. 491.

[11] N. Mohri, N. Saito, Y. Tsunekawa, Ann. CIRP 42 (1993) 219.

[12] J. Simao, H.G. Lee, D.K. Aspinwall, R.C. Dewes, E.M. Aspinwall, Int. J. Mach. Tools Manuf. 43 (2003) 121.

[13] H.C. Tsai, B.H. Yan, F.Y. Huang, Int. J. Mach. Tools Manuf. 43 (2003) 245.

[14] S.L. Chen, B.H. Yan, F.Y. Huang, J. Mater. Process. Technol. 87 (1999) 107.

[15] M.K. Meyer, A.J. Thom, M. Akinc, Intermetallics 7 (1999) 153.

[16] W. König, R. Wertheim, Y. Zvirin, Ann. CIRP 24 (1975) 95.

[17] D.D. Dibitonto, P.T. Eubank, M.R. Patel, M.A. Barrufet, J. Appl. Phys. 66 (1989) 4095.

[18] M.R. Patel, M.A. Barrufet, P.T. Eubank, D.D. Dibitonto, J. Appl. Phys. 66 (1989) 4104.

[19] Y. Tsunekawa, M. Okumiya, N. Mohri, I. Takahashi, Mater. Sci. Eng., A Struct. Mater: Prop. Microstruct. Process. 174 (1994) 193.

[20] L.C. Lee, L.C. Lim, V. Narayanan, V.C. Venkatesh, Int. J. Mach. Tools Manuf. 28 (4) (1988) 359.

[21] L.C. Lee, L.C. Lim, Y.S. Wong, H.S. Fong, J. Mater. Process. Technol. 29 (1992) 213.

[22] N.B. Vargaftik, Handbook of Physical Properties of Liquids and Gases, 2nd edition, Hemisphere Publishing Corporation, London, 1983, p. 49 \& p. 692. 